OPEN ACCESS

Edited by:

loan Andrei Veresiu,

Iuliu Hațieganu University of

Medicine and Pharmacy, Romania

Reviewed by:

Haroldo A. Toque,

Georgia Health Sciences University,

USA

Aaron Hanukoglu,

Tel-Aviv University, Israel

*Correspondence:

Marcus Lindenberger

marcus.lindenberger@liu.se

Specialty section:

This article was submitted to

Diabetes,

a section of the journa

Frontiers in Endocrinology

Received: 24 May 2016

Accepted: 30 August 2016

Published: 21 September 2016

Citation:

Lindenberger M (2016) Reduced Venous Compliance in Young Women

with Type 1 Diabetes - Further

Aggravated by Prolonged Elevated

Levels of HbA1c.

Front. Endocrinol. 7:126.

doi: 10.3389/fendo.2016.00126

\section{Reduced Venous Compliance in Young Women with Type 1 Diabetes - Further Aggravated by Prolonged Elevated Levels of HbA1c}

\author{
Marcus Lindenberger* \\ Department of Cardiology and Department of Medical and Health Sciences, Linköping University, Linköping, Sweden
}

Background: Young patients with diabetes present with reduced compensatory responses to hypovolemic stress. Less compliant veins could be a contributing factor, since roughly two-thirds of the blood volume resides in the venous system as a blood reservoir, adjusting proper venous inflow to the heart. The aim of this study was to measure venous compliance and lower limb blood pooling during hypovolemic stress, and to correlate them to indices of diabetes severity and glucose control.

Methods: Fifteen young women with type 1 diabetes (DW) and 18 healthy age-matched women (C) were subjected to lower body negative pressure (LBNP) (11-44 mmHg), creating hypovolemic stress. Lower limb blood pooling was measured with strain gage technique and venous compliance calculated as the relationship between $\Delta \mathrm{V} / \Delta \mathrm{P}$.

Results: DW presented with reduced blood pooling (e.g., blood pooling during LBNP of $44 \mathrm{mmHg}$, DW, $1.69 \pm 0.10 ; \mathrm{C}, 2.10 \pm 0.08(\mathrm{ml} / 100 \mathrm{ml})$, and $P=0.003)$. Calculated venous compliance was also reduced in DW (e.g., compliance at $20 \mathrm{mmHg}$, DW, $0.046 \pm 0.003 ; \mathrm{C}, 0.059 \pm 0.002(\mathrm{ml} / 100 \mathrm{ml} / \mathrm{mmHg})$, and $P=0.002)$. A progressive reduction in both venous compliance $(P<0.007)$ and blood pooling $(P<0.005)$ was seen with increasing level of $\mathrm{HbA} A_{1 c}$, and furthermore, less strongly associated with presence of microvascular disease (signs of retinopathy).

Conclusion: Women with type 1 diabetes present with both reduced venous compliance and blood pooling. The reductions were particularly present in patients with long-standing poor glycemic control.

Keywords: type 1 diabetes, venous compliance, HbA1c, hemodynamics, retinopathy, women

\section{INTRODUCTION}

Orthostatic hypotension is more common in people with type 1 diabetes (1-4). Diabetes is also associated with hemodynamic instability and reduced tolerance to rapidly induced hypovolemia (e.g., during anesthesia) $(1,2,5)$ and prolonged hypovolemia (e.g., hemodialysis) (6), aggravated with the presence of cardiovascular autonomic neuropathy $(\mathrm{CAN})(2,4,5)$. Nevertheless, diabetes patients without signs of or only mild CAN are also at risk of hypotension during orthostatic stress and anesthesia, pointing toward other causal factors involved $(1,5)$. 
Lower body negative pressure (LBNP) is a well-proven technique to mimic orthostatic and central hypovolemic stress by pooling blood in the lower part of the body (7). Reduced lower limb blood pooling has previously been noted in men with type 1 diabetes, further associated with reduced blood pooling in men with detectable microvascular disease (8). Reduced venous compliance has been noted in subjects with diabetes $(9,10)$, but not studied in conjunction with orthostatic stress. Reduced venous compliance could be beneficial during orthostatic stress, reducing the amount of blood pooled in the lower limbs (11). However, reduced venous compliance could also be detrimental. High vessel wall compliance is mandatory for efficient mobilization of peripheral venous capacitance blood to the central circulation to uphold venous return, cardiac output, and blood pressure during an orthostatic challenge $(12,13)$, We have recently presented reduced mobilization of peripheral capacitance blood in both men and women with type 1 diabetes $(8,14)$, aggravated with the severity of the disease, i.e., presence of microvascular disease (8) and level of $\mathrm{Hb}_{\mathrm{Alc}}$ (14). Female gender seems especially predisposed to diabetes-associated reduction in compliance with major elastic arteries (15). Furthermore, young healthy women have lower tolerance to orthostatic stress than men (16). Reduced speed of initial blood pooling has been linked with orthostatic intolerance in women (17). Collectively, this indicates young women with diabetes as a particularly interesting group to study.

The aim of this present study was to assess venous compliance and lower limb blood pooling in healthy women and in young women with type 1 diabetes and, furthermore, to correlate venous compliance with known risk factors associated with type 1 diabetes (e.g., age of diabetes onset, diabetes duration, presence of microvascular disease, and level of glycated hemoglobin). We hypothesized that venous compliance and blood pooling would be reduced in women with type 1 diabetes, and that the reductions would be associated with markers of diabetes severity.

\section{MATERIALS AND METHODS}

\section{Participants}

Women with type 1 diabetes enrolled as outdoor patients at the Department of Endocrinology at Linkoping University Hospital were asked to participate in the study if they met the inclusion and exclusion criteria. The inclusion criteria were: age between 18 and 30 years, duration of diabetes of at least 5 years, and willingness to participate in the study. Exclusion criteria: current smoking, sedentary lifestyle/obesity, and cardiovascular disease. Fifteen women with type 1 diabetes (DW) were included in the study. They were all on a multiple-dose insulin regime or treated with insulin pump without any other chronic cardiovascular medication. HbAlc was analyzed with Mono S-technique and then calculated to IFCC values using the formula: HbA1c IFCC $(\mathrm{mmol} / \mathrm{mol})=10.45 \times[\mathrm{HbA} 1 \mathrm{c}$, Mono S \% $]-10.62 . \mathrm{HbA}_{\mathrm{lc}}$ in DW were $66 \pm 2 \mathrm{mmol} / \mathrm{mol}$ (range $47-82 \mathrm{mmol} / \mathrm{mol}$ ), reference value $<45 \mathrm{mmol} / \mathrm{mol}$, with background data in DW presented in Table 1. Eighteen healthy age-matched women (C) were selected from the general population after public advertising meeting the same inclusion/exclusion criteria as DW with the exception for type 1 diabetes. See Table 2 for cardiovascular data. A recent study focusing on cardiovascular compensatory responses to hypovolemic stress (including mobilization of peripheral blood to central circulation and net fluid absorption of extravascular fluid) included all DW and 16 controls (14). Two additional healthy women were included in the present study, previously excluded from (14) due to missing key measurements in homeostatic regulation. As such, the present study and recent study (14) share basal resting cardiovascular parameters. On the other hand, venous compliance has not previously been studied in our research group in either men or women with type 1 diabetes. Subgroup analyses were conducted for differences in glycemic control, the presence of microvascular disease, and other parameters presented in Table 1. In order to elucidate the effect of hyperglycemia over time, mean $\mathrm{HbA}_{1 \mathrm{c}}$ from 5 years preceding the study was calculated $\left[\mathrm{HbA}_{1 \mathrm{c} 5}\right.$, in analogy with $\left.(14,18)\right]$ being $67 \pm 2 \mathrm{mmol} / \mathrm{mol}$ (range $51-84 \mathrm{mmol} / \mathrm{mol}$ ) in $\mathrm{DW}$, while $\mathrm{HbA}_{\mathrm{cc}}$ in $\mathrm{C}(n=8)$ was (31 $\pm 1 \mathrm{mmol} / \mathrm{mol}$, range $26-33 \mathrm{mmol} / \mathrm{mol}$, measured once). Based on their $\mathrm{HbA}_{1 \mathrm{c}}$, all participating women were divided into four subgroups: normal $(n=18)\left(\mathrm{HbA}_{1 \mathrm{c} 5}<45 \mathrm{mmol} / \mathrm{mol}\right)$; mild $(n=5)\left[\mathrm{HbA}_{1 \mathrm{c} 5}\right.$ range $51-60 \mathrm{mmol} / \mathrm{mol}$ (mean $56 \pm 2 \mathrm{mmol} /$ $\mathrm{mol})]$; moderate $(n=5)\left[\mathrm{HbA}_{\mathrm{lc5}}\right.$ range $61-70 \mathrm{mmol} / \mathrm{mol}$ (mean $67 \pm 2 \mathrm{mmol} / \mathrm{mol})]$; poor $(n=5)\left[\mathrm{HbA}_{1 \mathrm{c} 5} \mathrm{range}>70 \mathrm{mmol} /\right.$ mol (mean $77 \pm 2 \mathrm{mmol} / \mathrm{mol}$ )] (overall subgroup reduction

TABLE 1 | Characteristics of women with type 1 diabetes.

\begin{tabular}{lcc}
\hline Parameter & Mean + SE & Range \\
\hline Age at onset of diabetes, years & $11 \pm 1$ & $1-19$ \\
Duration of diabetes, years & $13 \pm 1$ & $5-23$ \\
$\mathrm{HbA}_{1 \mathrm{c}}$ at study, $\mathrm{mmol} / \mathrm{mol}$ & $66 \pm 2$ & $47-82$ \\
Mean $_{\mathrm{HbA}} \mathrm{cc5}, \mathrm{mmol} / \mathrm{mol}$ & $67 \pm 2$ & $51-84$ \\
Hemoglobin, g/dl & $13.8 \pm 0.1$ & $12.8-14.9$ \\
GRF, ml/min/1.73 m² & $93 \pm 3$ & $71-124$ \\
Total cholesterol, mmol/l & $4.3 \pm 0.2$ & $3.4-6.2$ \\
Albuminuria, mg/mmol & $6 \pm 2$ & $0-16$ \\
Total insulin dosage/day, IE & $49 \pm 4$ & $25-82$ \\
Insulin dosage/body weight, E/kg & $0.73 \pm 0.05$ & $0.35-1.16$ \\
Blood glucose level, mmol/l & $8.7 \pm 1$ & $4.2-12.8$ \\
Retinopathy, background & 7 & \\
Retinopathy, proliferative & 0 & \\
Neuropathy & 0 & \\
Nephropathy & 0 &
\end{tabular}

TABLE 2 | Cardiovascular parameters in DW and C.

\begin{tabular}{lccl}
\hline Parameter & DW & C & P-value \\
\hline $\mathrm{N}$ & 15 & 18 & \\
$\mathrm{HR}$, beats/min & $69 \pm 2$ & $57 \pm 1$ & $\mathbf{0 . 0 0 0 1}$ \\
$\mathrm{SBP}, \mathrm{mmHg}$ & $110 \pm 2$ & $105 \pm 1$ & 0.06 \\
$\mathrm{DBP}, \mathrm{mmHg}$ & $61 \pm 1$ & $65 \pm 1$ & $\mathbf{0 . 0 4}$ \\
$\mathrm{MAP}, \mathrm{mmHg}$ & $78 \pm 1$ & $78 \pm 1$ & 0.98 \\
$\mathrm{PP}, \mathrm{mmHg}$ & $49 \pm 2$ & $41 \pm 2$ & $\mathbf{0 . 0 0 1}$ \\
FBF, $\mathrm{ml} / \mathrm{100} \mathrm{ml} / \mathrm{min}$ & $2.6 \pm 0.2$ & $1.9 \pm 0.2$ & $\mathbf{0 . 0 1}$ \\
FVR, units & $31 \pm 2$ & $45 \pm 3$ & $\mathbf{0 . 0 0 3}$ \\
FVC, units $\left(\mathrm{E}^{-3}\right)$ & $34 \pm 2$ & $25 \pm 2$ & $\mathbf{0 . 0 2}$ \\
$\mathrm{P}-\mathrm{NE}, \mathrm{pmol} / \mathrm{l}$ & $1.2 \pm 0.2$ & $1.2 \pm 0.1$ & 0.70 \\
\hline
\end{tabular}

$H R$, heart rate; SBP, systolic blood pressure; $D B P$, diastolic blood pressure; $M A P$, mean arterial pressure; PP, pulse pressure; FBF, forearm blood pressure; FVR, forearm vascular resistance; $F V C$, forearm vascular conductance; $P-N E$, plasma norepinephrine. Bold expresses significant group differences. 
in $\mathrm{HbA}_{1 \mathrm{c} 5}, P<0.0001$; mild vs. moderate, $P=0.005$ and poor, $P=0.0005$; moderate vs. poor $P=0.01$ ). Microvascular disease was present in seven DW (all diagnosed with background retinopathy of whom four with minimal or slight background retinopathy), comprising the subgroup of RET+, while the remaining eight DW without signs of retinopathy formed RET-. All women were scheduled in the middle part of the menstrual cycle, with $9 \mathrm{C}$ and $6 \mathrm{DW}$ on oral contraceptives. No impact of menstrual cycle or oral contraceptives have been seen on venous compliance $(12,19)$. Each subject provided written informed consent to the experiments approved by the local Ethics Committee of Linkoping University and conformed to the Declaration of Helsinki.

\section{Lower Body Negative Pressure}

The experiments started $1 \mathrm{~h}$ after a light meal randomly in the morning or afternoon. No circadian variations have been seen in previous, similar experiments in our lab (12). Room temperature was held constant between 23 and $25^{\circ} \mathrm{C}$ to avoid the subjects to get chilled. The subjects were instructed to abstain from caffeine on the day of investigation. DW were instructed to take their ordinary insulin doses prior to the experiment. The subjects were placed in the supine position with the lower part of the body up to the level of the iliac crest enclosed in an airtight box connected to a vacuum source, enabling stable negative pressure to be produced within $5 \mathrm{~s}$ (LBNP), continuously measured and held constant by a rheostat. During LBNP, $80 \%$ of the negative pressure is transmitted to the underlying muscle tissue of the leg irrespective of muscle depth, time, and magnitude, leading to a defined increase in transmural pressure over the vessel wall, with a concomitant vessel dilatation and blood pooling (11).

\section{Lower Limb Blood Pooling}

To measure the amount of blood pooling evoked by LBNP, calf volume changes $(\mathrm{ml} / 100 \mathrm{ml})$ were measured with mercury-insilicone strain gage plethysmography applied at the maximal circumference of the right calf. To avoid any confounding external tissue pressure, the lowest part of the calf was $2 \mathrm{~cm}$ above the floor of the LBNP chamber. The subjects rested in the supine position for at least $30 \mathrm{~min}$ to ensure stable calf volume and arterial inflow prior to the start of experiments. Interindividual supine resting venous pressure has been shown to be fairly constant (20).

Momentarily after LBNP initiation, a rapid increase in calf volume is seen (blood pooling) followed by a slower, but continuous rise caused by net capillary fluid filtration from blood to surrounding tissue. At cessation, there is a rapid decrease in calf volume corresponding with the increase at onset of LBNP (21). Fully developed blood pooling is achieved well within 3 min at LBNP levels used in the present study, and net capillary fluid filtration continually and linearly increases calf volume thereafter (21). The blood pooling was, therefore, calculated from calf volume at baseline to the line defined from the filtration slope $(14,21)$. The reproducibility of venous blood pooling measurements with this approach is good $(\mathrm{CV}<10 \%)(22)$. We also assessed calf volume increase (every $5 \mathrm{~s}$ ) and calculated mean rate of blood pooling $(\mathrm{ml} / 100 \mathrm{ml} / \mathrm{min})$ during the first min of LBNP.
After at least $30 \mathrm{~min}$ of complete rest in the supine position, LBNP of $11 \mathrm{mmHg}$ was applied for 4-6 min followed by complete rest for 5-10 min. LBNP of 22 and $44 \mathrm{mmHg}$ was then applied in similar fashion with rest in between. Continuous recordings of calf volume ensured that basal calf volume was restored and stable before each LBNP session. Continuous, online recordings confirmed a clear and stable filtration slope for at least $2 \mathrm{~min}$ used to separate blood pooling from net fluid filtration. The above protocol was in the majority of cases repeated, and the mean blood pooling was calculated. The lower LBNP pressure $(11 \mathrm{mmHg})$ was chosen since change in calf volume below LBNP pressures of $10 \mathrm{mmHg}$ may be dependent on other parameters than venous filling, not reflecting venous wall properties (23). The upper limit was chosen to avoid presyncope, frequently known to occur in women at LBNP levels over $45-50 \mathrm{mmHg}(16,17)$, and men with type 1 diabetes have shown signs of hemodynamic instability well below this level (8). After correcting for LBNP pressure transmission of roughly $80 \%$ (11), the studied venous transmural pressure interval was $9-36 \mathrm{mmHg}$, a range previously applied to both healthy subjects and men with type 1 diabetes $(8,17,22-24)$.

\section{Venous Compliance}

Calf venous compliance $(\mathrm{ml} / 100 \mathrm{ml} / \mathrm{mmHg})$ was measured by a modified version of the technique developed by Olsen and Lanne (11) and previously used $(22,23)$. In each subject, the LBNP-evoked blood pooling were plotted against the prevailing transmural pressure of 9, 18, and $36 \mathrm{mmHg}$ (Figure 2A). The resulting blood pooling-pressure curve was non-linear, with larger volume changes (greater compliance) at lower transmural pressures as described by a quadratic regression equation:

$$
\begin{aligned}
\Delta \text { Calf volume }= & \beta_{0}+\beta_{1} \cdot(\text { transmural pressure }) \\
& +\beta_{2} \cdot(\text { transmural pressure })^{2}
\end{aligned}
$$

$\beta_{0}$ is the $y$-intercept, and $\beta_{1}$ and $\beta_{2}$ are characteristics of the slope of the volume-pressure curve. This equation showed an excellent mathematical fit to the measured data points (Figure 2A). Since compliance is altered with changes in pressure, no single value can characterize the slope of this relation. The first derivative of the volume-pressure curve [Compliance $=\beta_{1}+\left(2 \cdot \beta_{2} \cdot\right.$ transmural pressure)] was then calculated, creating a linear compliance-pressure curve (Figure 2B). Calf venous compliance was then calculated at various transmural pressures, in both the high and low ranges (Figure 2B). The use of the quadratic regression equation as a surrogate for true venous compliance is widely accepted, based on the work by Halliwill et al. (25).

In conjugation with the experiment described above, cardiovascular parameters were monitored, e.g., brachial blood pressure (Dinamap Pro 200, Critikon, Tampa, FL, USA) and forearm blood flow (FBF) [standard venous occlusion strain gage plethysmography (Hokanson EC-6, D. E. Hokanson, Bellevue, WA, USA)] (14).

\section{Statistical Evaluation}

Values are expressed as means \pm SE, unless stated otherwise. Group differences in blood pooling and calculated venous compliance were assessed using unpaired Student's $t$-test. Bonferroni corrections were applied in subgroup analyses. One-way ANOVAs 
were applied to assess differences in continuous parameters (e.g., compliance at $20 \mathrm{mmHg}$ ) when studying subgroups as nominals (e.g., quartile groups based on $\mathrm{HbA}_{1 \mathrm{c} 5}$ ). Two-way repeated measures ANOVAs were applied to assess group differences in blood pooling over transmural pressure of $9-36 \mathrm{mmHg}$ and rate of blood pooling during the first $60 \mathrm{~s}$ of LBNP. Regression analyses were applied to assess correlations between continuous parameters of diabetes (e.g., duration of diabetes; see Table 1) and blood pooling as well as venous compliance. $P<0.05$ was considered statistically significant.

\section{RESULTS}

\section{Baseline Characteristics}

DW were slightly older than C (DW, $24.6 \pm 0.8$; C, $22.8 \pm 0.3$ years, and $P<0.05$ ). No differences were seen in body height (DW, $1.66 \pm 0.02 ; \mathrm{C}, 1.70 \pm 0.02 \mathrm{~m}$ ) or body weight (DW, $66 \pm 2$; C, $62 \pm 2 \mathrm{~kg}$ ), with body mass index (BMI) slightly higher in DW, but well within normal range (DW, $23.7 \pm 0.5$; C, $21.2 \pm 0.4 \mathrm{~kg} /$ $\left.\mathrm{m}^{2}, P<0.01\right)$. Please see Table 2 for full cardiovascular characteristics at rest in both groups. DW presented with elevated resting heart rate $(P<0.0001)$ and increased pulse pressure $(P<0.001)$.

\section{Blood Pooling and Venous Compliance}

Figure 1 shows blood pooling evoked by LBNP of $22 \mathrm{mmHg}$ plotted against its induced transmural pressure, with a clear correlation seen $(r=0.71, P<0.0001)$. Figure $2 \mathrm{~A}$ present calf blood pooling brought on by LBNP of 11, 22, and $44 \mathrm{mmHg}$ (equivalent to transmural pressure of 9,18 , and $36 \mathrm{mmHg}$ ) as well as the line calculated by the quadratic regression equation during transmural pressure of $10-35 \mathrm{mmHg}$. Blood pooling $(\mathrm{ml} / 100 \mathrm{ml})$ was reduced in DW during LBNP of $22 \mathrm{mmHg}$ (DW $1.09 \pm 0.07 ; \mathrm{C}, 1.25 \pm 0.06, P<0.05)$ and LBNP of $44 \mathrm{mmHg}(\mathrm{DW}, 1.69 \pm 0.10 ; \mathrm{C}, 2.10 \pm 0.08, P=0.003)$ as well as overall reduced during the whole pressure range $(10-35 \mathrm{mmHg}$, $P<0.05)$ and a more flat slope with increased transmural pressure in DW $(P<0.0001)$. The rate of calf volume increase

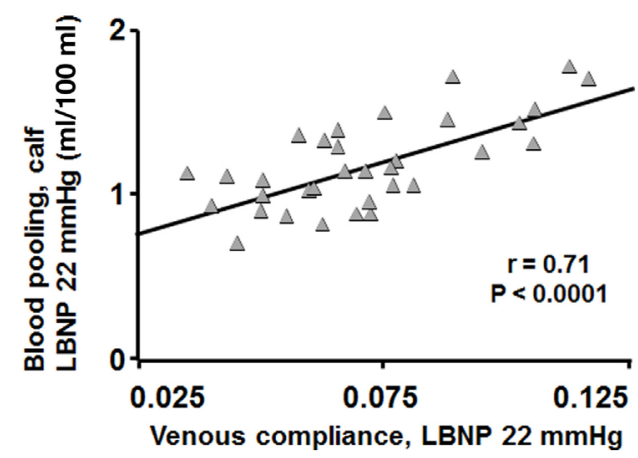

FIGURE 1 | Blood pooling in DW and C during LBNP of $22 \mathrm{mmHg}$ plotted against their calculated venous compliance at concomitant evoked transmural pressure (gray triangles). Blood pooling correlated well with venous compliance $(r=0.71, P<0.0001)$. (reflecting rate of blood pooling) during the first minute of LBNP $22 \mathrm{mmHg}$ was similar in DW and C $(P=0.70)$. Figure 2B depicts the corresponding calf venous compliance in DW and C. Venous compliance $(\mathrm{ml} / 100 \mathrm{ml} / \mathrm{mmHg})$ was reduced in DW, both overall $(P=0.0007)$ as well as during calculated compliance between transmural pressure of 15-35 $\mathrm{mmHg}$ (e.g., compliance at $20 \mathrm{mmHg}, \mathrm{DW}, 0.046 \pm 0.003 ; \mathrm{C}, 0.059 \pm 0.002$, $P=0.002)$. The two separate components for venous compliance calculation were: $\beta_{1}, 0.081 \pm 0.009$ in DW and $0.092 \pm 0.007$ in $\mathrm{C} ; \beta_{2},-0.00088 \pm 0.00015$ in DW and $-0.00084 \pm 0.00015$ in C.

\section{HbA1c in Correlation with Blood Pooling and Venous Compliance}

Figure $3 \mathrm{~A}$ shows blood pooling in the calf divided into four groups based on mean $\mathrm{HbA}_{1 \mathrm{c}}$ the last 5 years $\left(\mathrm{HbA}_{1 \mathrm{c} 5}\right)$. Blood pooling was progressively reduced in groups with increasing $\mathrm{HbA}_{1 c 5}(P=0.005)$. Women with normal $\mathrm{HbA}_{1 c 5}$ had significantly greater blood pooling during LBNP of $44 \mathrm{mmHg}$ than women with moderate and severe $\mathrm{HbA}_{1 c 5}(P=0.02$ and $P=0.001$, respectively), but no statistical differences were seen between the other three groups. Figure 3B presents corresponding venous compliance in analogous groups, with progressively reduced venous

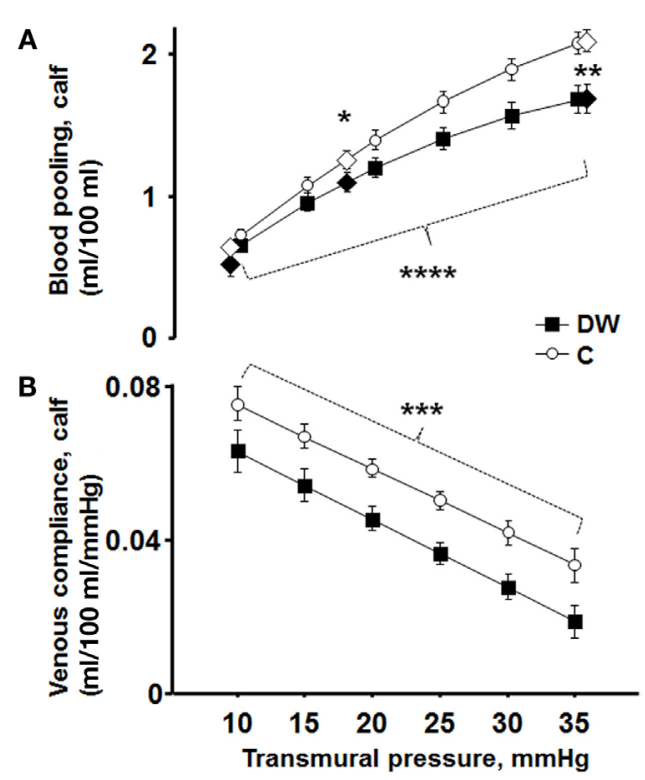

FIGURE 2 | (A) Blood pooling at LBNP of 11, 22, and $44 \mathrm{mmHg}$ (equivalent to transmural pressure of 9,18 , and $36 \mathrm{mmHg}$ ) in DW (black diamonds) and $\mathrm{C}$ (white diamonds). The from the quadratic regression equation calculated volume is depicted in two black lines marked every $5 \mathrm{mmHg}$ (DW black boxes; $C$ white circles). Blood pooling $(\mathrm{ml} / 100 \mathrm{ml})$ was reduced in DW during LBNP of $22 \mathrm{mmHg}(P<0.05)$ and LBNP of $44 \mathrm{mmHg}(P=0.003)$. The shape of the line was more horizontal in DW with increased transmural pressure, i.e., blood pooling increased less with enhanced transmural pressure in DW $(P<0.0001)$. (B) Corresponding calf venous compliance in DW (black boxes) and C (white circles). Venous compliance (ml/100 ml/ $\mathrm{mmHg}$ ) was reduced in DW, both overall $(P=0.0007)$ as well as during calculated venous compliance (e.g., compliance at LBNP $22 \mathrm{mmHg}$, $P=0.002)$. 

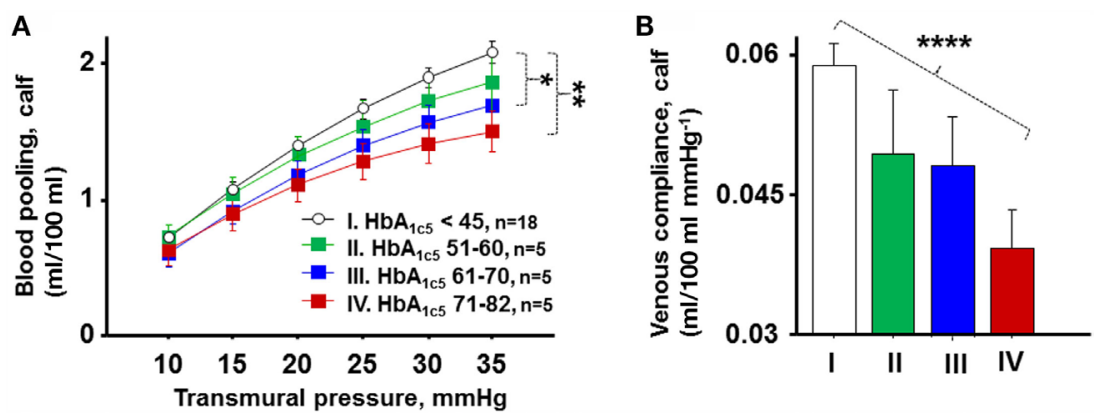

FIGURE 3 | (A) Calf blood pooling divided into four groups based on $\mathrm{HbA}_{1 \mathrm{c}}$ denoted normal (I, white circles, $n=18$ ), mild (II, green boxes, $n=5$ ), moderate (III, blue boxes, $n=5)$, and poor (IV, red boxes, $n=5$ ). Blood pooling was progressively reduced in groups with increasing $\mathrm{HbA}_{1 c 5}(P=0.005)$. Women with normal $\mathrm{Hb} \mathrm{A}_{105}$ had significantly greater blood pooling during LBNP of $44 \mathrm{mmHg}$ than women with moderate and severe $\mathrm{HbA}_{1 c 5}(P=0.02$ and $P=0.001$, respectively). (B) Corresponding mean venous compliance during transmural pressure of $10-35 \mathrm{mmHg}$ in analogous groups (I-IV). A progressive reduction in venous compliance with increasing $\mathrm{HbA}_{1 c 5}$ throughout the studied pressure range of $10-35 \mathrm{mmHg}$ was seen $(P<0.0001)$.

compliance with increasing $\mathrm{HbA}_{1 \mathrm{c} 5}(P<0.0001)$. A calculated venous compliance during transmural pressure of $20 \mathrm{mmHg}$ was likewise progressively reduced in a similar fashion with increasing $\mathrm{HbA}_{1 \mathrm{c} 5}(P=0.007)$.

Figure 4 shows the correlation between level of $\mathrm{HbA}_{1 \mathrm{c} 5}$ and the rate of calf volume increase $(\mathrm{ml} / 100 \mathrm{ml} / \mathrm{sec}) 30-60 \mathrm{~s}$ after LBNP initiation in DW, with a negative correlation seen $(r=-0.72$, $P=0.002$ ), i.e., the higher the $\mathrm{HbA}_{1 \mathrm{c} 5}$ value, the slower the blood pooling rate.

\section{Retinopathy in Correlation with Blood Pooling and Venous Compliance}

$\mathrm{HbA}_{1 \mathrm{lc5}}$ tended to be increased in RET + compared to RET$(P=0.06)$. Figure $5 \mathrm{~A}$ shows blood pooling evoked by LBNP depicted in C, RET-, and RET+. C seemingly pooled the greatest amount of blood, followed by RET - and RET+, with a progressive reduction in blood pooling $(P=0.003)$, a pattern also recurring at LBNP-induced blood pooling of $44 \mathrm{mmHg}$ $(P=0.008)$. Figure 5B depicts corresponding venous compliance with gradually reduced venous compliance in C, RET-, and $\mathrm{RET}+(P<0.0001)$. A calculated venous compliance during transmural pressure of $20 \mathrm{mmHg}$ was also correspondingly reduced $(P=0.003)$. No significantly detectable differences were seen between RET + and RET - in blood pooling $(P=0.12)$ or venous compliance $(P=0.16)$.

\section{Blood Pooling, Venous Compliance, and Other Parameters of Disease Severity}

Blood pooling and venous compliance were also compared with parameters stated in Table $\mathbf{1}$ (e.g., duration of diabetes and insulin dosage per kilogram body weight). Resting heart rate (here used as a surrogate marker for autonomic dysfunction) showed a weak, but significant, negative correlation with blood pooling at LBNP of $44 \mathrm{mmHg}(R=-0.37, P=0.03)$ and reduced venous compliance in all women studied $(P=0.04)$. Although some significant correlations fell out randomly between the parameters and blood pooling/venous compliance, no consistent patterns or correlations were seen.

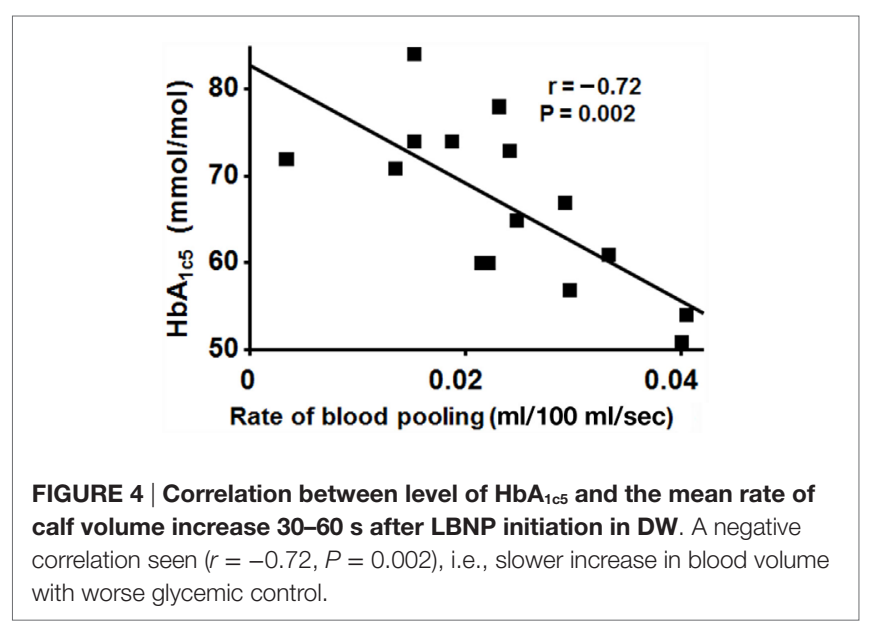

\section{DISCUSSION}

The main findings in the present study were: blood pooling and venous compliance in the lower limb were reduced in women with type 1 diabetes. Worse glycemic control, but also the presence of microvascular disease and signs of autonomic dysfunction, were associated with further reduction in blood pooling and venous compliance.

\section{Hemodynamic Stability in Diabetes}

Patients with diabetes are prone to hemodynamic instability and present with reduced tolerance to hypovolemia, most prominent in the short term during change from supine to erect body position and during anesthesia (1-4). The present study focuses mainly on these short-term hemodynamic effects of diabetes. LBNP is a widely used model for hypovolemic and orthostatic stress, mimicking the rapidly induced central hypovolemia when shifting body position from supine to erect, unloading the baroreceptors (7). Roughly, $70 \%$ of the total blood volume resides in the systemic veins, important for maintaining hemodynamic stability by serving for proper venous return to 

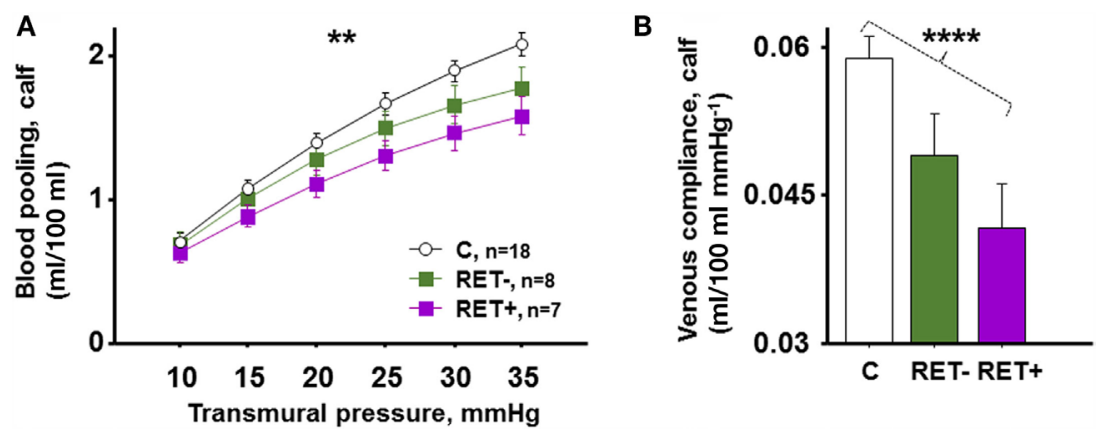

FIGURE 5 | (A) LBNP-induced blood pooling in C ( $n=18)$, RET- (DW with no signs of retinopathy, $n=8)$ and RET+ (DW with signs of retinopathy, $n=7)$. C pooled the greatest amount of blood, followed by RET - and RET+, with progressively reduced blood pooling seen in this order $(P=0.003)$. (B) Corresponding mean venous compliance during transmural pressure of $10-35 \mathrm{mmHg}$ in identical groups, with gradually reduced venous compliance in $\mathrm{C}$, RET-, and RET+ $(P<0.0001)$.

the right atrium (26). Compliant capacitance veins (great blood mobilization for each small reduction in venous pressure) is, therefore, a key factor in maintaining hemodynamic stability, e.g., during rapid changes in body position (13). However, it is a double-edged sword, where highly compliant veins could predispose for orthostatic hypotension as a result of a large shift of blood to the lower limbs during erect position, seen in the present study with greater blood pooling in women the greater the venous compliance (Figure 1).

\section{Venous Compliance and Blood Pooling in Diabetes}

Venous compliance was reduced in DW (Figure 2B), in analogy with two previous studies on venous compliance and diabetes $(9,10)$. Venous compliance has not earlier been studied in diabetes in conjunction with orthostatic stress and its implications. We extend on previous findings by presenting reduced blood pooling in DW (Figure 2A), which could as such serve as a protective mechanism against orthostatic hypotension in DW (smaller decrease in central blood volume), counterbalancing the occurrence of autonomous dysfunction $(2,4,27)$.

Men with type 1 diabetes present with reduced blood pooling only when microvascular disease was present $(8,28)$. Venous compliance was, however, not calculated in these studies. The role of type 1 diabetes in stiffening of elastic arteries (compliance reduction) also seem more prominent in women with type 1 diabetes than men (15). Young women also have lower tolerance to orthostatic stress than men (16), collectively emphasizing the importance to study blood pooling and venous compliance in women with type 1 diabetes.

The reduced venous compliance could in part explain the seen reduction in hypovolemic stress-induced compensatory mobilization of capacitance blood in diabetes $(8,14)$. Both lower limb blood pooling and compensatory mobilization of capacitance blood has been linked with diabetes severity $(8,14)$. With this in mind, a sub study was conducted, comparing blood pooling and venous compliance with various markers of diabetes severity (Table 1). In the commencing sub studies, the number of women with diabetes in each subgroup were small $(n=5)$, and as such, the results must be interpreted with caution. Nevertheless, significant findings in line with the hypothesis of the study and the pathophysiology of diabetes were found.

\section{Levels of HbA1c, Blood Glucose, and Insulin Dosage}

Both blood pooling and venous compliance decreased with increasing level of $\mathrm{HbA}_{1 \mathrm{c} 5}$ (Figures 3A,B). Prolonged poor glycemic control was also associated with slower pooling of blood in the lower limb (Figure 4). The slower blood pooling could be an independent contributing factor to hemodynamic instability seen in diabetes during orthostatic stress $(4,17)$ It is well known that poor glycemic control over time increases glycation of proteins, undergoing complex reactions to become irreversibly cross-linked, termed advanced glycation end products (AGEs). AGEs accumulate on collagen and elastin in the vessel wall and are likely involved in the increase in vascular stiffness seen in diabetes (29-31). It seem plausible that poor glycemic control and increased amount of AGEs contribute to reduce compliance also on the venous side. In analogy, mean level of $\mathrm{HbA}_{1 \mathrm{c}}$ in the 5 years preceding the study showed a stronger negative correlation with venous compliance than level of $\mathrm{HbA}_{1 \mathrm{c}}$ at the time of the study, further corroborated with the lack of association between levels of blood glucose during experiments and venous compliance. Insulin is known to affect various parts of the cardiovascular system, but we found no correlation between daily insulin dose or insulin dosage per kilogram body weight and venous compliance. Taken together, it seems that the reduction in venous compliance in diabetes is caused by long-term effects of diabetes rather than short-term differences in blood glucose or insulin.

\section{Presence of Microvascular Disease and Autonomic Dysfunction}

Clinical examination revealed evidence of background retinopathy in seven DW, with four of these categorized as slight or minimal and none with proliferative retinopathy. As such, none of the DW had more than mild microvascular engagement, and no one presented with clinical signs of neuropathy or nephropathy (Table 1). Both reduced venous compliance and blood pooling were seen when dividing the women into groups of healthy, RET - and RET+ (Figure 5; $P<0.0001$ ). 
However, no statistically significant difference was seen between RET - and RET+ when comparing venous compliance $(P=0.16)$ and blood pooling $(P=0.12)$. This is in contrast to a previous study in men with diabetes, presenting reduced blood pooling with presence of microvascular disease (8). However, the male diabetics presented with more aggravated microvascular disease as well as evidence of neuropathy and/or nephropathy, possibly explaining the differences found (8).

\section{Other Signs of Diabetes Severity}

DW presented with increased heart rate at rest (Table 2), a sign of autonomic dysfunction (27). We saw no correlation between resting heart rate and venous compliance and blood pooling within DW alone. When pooling both groups together, a weak negative association was seen, i.e., the greater the heart rate, the lower the venous compliance (see Section "Results"). The finding could be a result of group differences between healthy controls and DW rather than influence of autonomic dysfunction on venous compliance. However, compensatory mobilization of venous capacitance blood during hypovolemic stress (dependent on high venous compliance) is clearly associated with autonomic dysfunction (14). This discrepancy could be explained by physiological differences, where venous compliance in the present study is measured within the transmural pressures range of $9-36 \mathrm{mmHg}$ and the decrease in transmural pressures in the venous section triggering compensatory mobilization of blood is well below $5 \mathrm{mmHg}$ (24). As such, it is likely that the autonomic dysfunction present in DW more prominently affects compliance in the low pressure area in early stages of the disease.

Cardiovascular autonomic neuropathy is common in diabetes patients and increases with duration of disease, although difficult to diagnose in its early stages $(2,32)$. No correlation was seen between venous compliance and age at onset of diabetes or duration of the disease. Furthermore, blood pooling and venous compliance were nowhere near associated with glomerular filtration rate (GFR), cholesterol level, or detectable microalbuminuria (Table 1).

The diabetes care in Linköping is of high international standard, and the participating young women with type 1 diabetes presented with overall good glycemic control and were free of aggravated microvascular disease (Table 1). In this setting, any possible association between diabetes severity and studied venous compliance and blood pooling in young women will be harder to

\section{REFERENCES}

1. Low PA, Benrud-Larson LM, Sletten DM, Opfer-Gehrking TL, Weigand SD, O'Brien PC, et al. Autonomic symptoms and diabetic neuropathy: a population-based study. Diabetes Care (2004) 27(12):2942-7. doi:10.2337/ diacare.27.12.2942

2. Vinik AI, Ziegler D. Diabetic cardiovascular autonomic neuropathy. Circulation (2007) 115(3):387-97. doi:10.1161/CIRCULATIONAHA.106. 634949

3. Hirai FE, Moss SE, Klein BE, Klein R. Postural blood pressure changes and associated factors in long-term Type 1 diabetes: Wisconsin Epidemiologic Study of Diabetic Retinopathy. J Diabetes Complications (2009) 23(2):83-8. doi:10.1016/j.jdiacomp.2008.01.002 detect. Further studies including middle-aged men and women with type 1 diabetes is therefore warranted.

\section{Limitations of the Study}

Calf venous compliance was measured in accordance with previously published work from our laboratory [e.g., Ref $(22,23)]$, by accurately decreasing extravascular tissue pressure (LBNP) to generate transmural pressure differences over the venous wall rather than increasing intravascular pressure with a thigh cuff (25). This approach has advantages in that it allows for easy adjustment of the prominent calf net fluid filtration present conjoined with blood pooling during both LBNP and cuff technique. We have worked with both techniques and feel that they both are reliable in measuring venous compliance.

\section{CONCLUSION}

Venous compliance was reduced in women with type 1 diabetes. Blood pooling at transmural pressures relevant to upright posture was also reduced in women with type 1 diabetes. Worse glycemic control over time was correlated with further aggravated reduction in venous compliance. These data suggest pathophysiological incorporation of advanced glycemic end products in the vessel wall contributing to the reduction in venous compliance. A less compliant venous system could contribute to the hemodynamic instability associated with diabetes.

\section{AUTHOR CONTRIBUTIONS}

ML was responsible for the study design, performed the experiments, compiled and interpreted the data, and drafted the manuscript.

\section{ACKNOWLEDGMENTS}

The author wishes to acknowledge the contribution to this work by late Dr. Torbjorn Lindstrom, especially in topics related to the women having type 1 diabetes.

\section{FUNDING}

This research was funded by grants from non-profit organizations: Futurum, County Council of Jonkoping; The County Council of Ostergotland.

4. Philips JC, Marchand M, Scheen AJ. Squatting, a posture test for studying cardiovascular autonomic neuropathy in diabetes. Diabetes Metab (2011) 37(6):489-96. doi:10.1016/j.diabet.2011.09.004

5. Huang CJ, Kuok CH, Kuo TB, Hsu YW, Tsai PS. Pre-operative measurement of heart rate variability predicts hypotension during general anesthesia. Acta Anaesthesiol Scand (2006) 50(5):542-8. doi:10.1111/j.1399-6576.2006.001016.x

6. Brunet P, Saingra Y, Leonetti F, Vacher-Coponat H, Ramananarivo P, Berland Y. Tolerance of haemodialysis: a randomized cross-over trial of 5-h versus 4-h treatment time. Nephrol Dial Transplant (1996) 11(Suppl 8):46-51. doi:10.1093/ndt/11.supp8.46

7. Convertino VA. Neurohumoral mechanisms associated with orthostasis: reaffirmation of the significant contribution of the heart rate response. Front Physiol (2014) 5:236. doi:10.3389/fphys.2014.00236 
8. Lindenberger $\mathrm{M}$, Olsen $\mathrm{H}$, Lanne $\mathrm{T}$. Impaired compensatory response to hypovolaemic circulatory stress in type 1 diabetes mellitus. Diab Vasc Dis Res (2011) 8(2):136-42. doi:10.1177/1479164111404576

9. Bell D, Collier A, Nicoll JJ, Jackson M, Millar AM, Clarke BF, et al. Reduced venous compliance and increased transcapillary escape of protein in insulin-dependent diabetic patients. Diabet Med (1988) 5(5):454-8. doi:10.1111/ j.1464-5491.1988.tb01027.x

10. Schaper NC, Houben AJ, Schoon Y, Kooman JP, Huvers FC, Nieuwenhuijzen Kruseman AC. Venous compliance and the venodilatory effect of nitroglycerin in insulin-dependent diabetic patients with and without (incipient) nephropathy. Eur J Clin Invest (1994) 24(6):382-7. doi:10.1111/j.1365-2362.1994. tb02180.x

11. Olsen H, Lanne T. Reduced venous compliance in lower limbs of aging humans and its importance for capacitance function. Am J Physiol (1998) 275(3 Pt 2):H878-86.

12. Lindenberger $\mathrm{M}, \mathrm{Olsen} \mathrm{H}$, Lanne $\mathrm{T}$. Lower capacitance response and capillary fluid absorption in women in order to defend central blood volume in response to acute hypovolemic circulatory stress. Am J Physiol Heart Circ Physiol (2008) 295(2):H867-73. doi:10.1152/ajpheart.00332.2008

13. Rothe CF. Venous system: physiology of the capacitance vessels. In: Shepherd J, editor. Handbook of Physiology. The Cardiovascular System, Peripheral Circulation. III. Washington, DC; Bethesda, MD: American Physiological Society (1983). p. 397-452.

14. Lindenberger $\mathrm{M}$, Lindstrom $\mathrm{T}$, Lanne $\mathrm{T}$. Decreased circulatory response to hypovolemic stress in young women with type 1 diabetes. Diabetes Care (2013) 36(12):4076-82. doi:10.2337/dc13-0468

15. Ryden Ahlgren A, Lanne T, Wollmer P, Sonesson B, Hansen F, Sundkvist G. Increased arterial stiffness in women, but not in men, with IDDM. Diabetologia (1995) 38(9):1082-9. doi:10.1007/BF00402179

16. Convertino VA. Gender differences in autonomic functions associated with blood pressure regulation. Am J Physiol (1998) 275(6 Pt 2):R1909-20.

17. Lindenberger $M$, Lanne $T$. Slower lower limb blood pooling in young women with orthostatic intolerance. Exp Physiol (2015) 100(1):2-11. doi:10.1113/ expphysiol.2014.082867

18. Yu Y, Thorpe SR, Jenkins AJ, Shaw JN, Sochaski MA, McGee D, et al. Advanced glycation end-products and methionine sulphoxide in skin collagen of patients with type 1 diabetes. Diabetologia (2006) 49(10):2488-98. doi:10.1007/ s00125-006-0355-8

19. Meendering JR, Torgrimson BN, Houghton BL, Halliwill JR, Minson CT. Effects of menstrual cycle and oral contraceptive use on calf venous compliance. Am J Physiol Heart Circ Physiol (2005) 288(1):H103-10. doi:10.1152/ ajpheart.00691.2004

20. Skoog J, Zachrisson H, Lindenberger M, Ekman M, Ewerman L, Lanne T. Calf venous compliance measured by venous occlusion plethysmography: methodological aspects. Eur J Appl Physiol (2015) 115(2):245-56. doi:10.1007/ s00421-014-3009-4

21. Lundvall J, Bjerkhoel P, Edfeldt H, Ivarsson C, Lanne T. Dynamics of transcapillary fluid transfer and plasma volume during lower body negative pressure. Acta Physiol Scand (1993) 147(2):163-72. doi:10.1111/j.1748-1716.1993. tb09485.x
22. Lindenberger $M$, Lanne T. Decreased capillary filtration but maintained venous compliance in the lower limb of aging women. Am J Physiol Heart Circ Physiol (2007) 293(6):H3568-74. doi:10.1152/ajpheart.00725.2007

23. Lindenberger M, Lanne T. Sex-related effects on venous compliance and capillary filtration in the lower limb. Am J Physiol Regul Integr Comp Physiol (2007) 292(2):R852-9. doi:10.1152/ajpregu.00394.2006

24. Olsen H, Lanne T. Reduced capillary hydraulic conductivity in skeletal muscle and skin in Type I diabetes: a possible cause for reduced transcapillary fluid absorption during hypovolaemia. Diabetologia (2000) 43(9):1178-84. doi:10.1007/s001250051510

25. Halliwill JR, Minson CT, Joyner MJ. Measurement of limb venous compliance in humans: technical considerations and physiological findings. J Appl Physiol (1999) 87(4):1555-63.

26. Rowell L. Human Cardiovascular Control. New York: Oxford University Press (1993).

27. Schonauer M, Thomas A, Morbach S, Niebauer J, Schonauer U, Thiele H. Cardiac autonomic diabetic neuropathy. Diab Vasc Dis Res (2008) 5(4):336-44. doi:10.3132/dvdr.2008.047

28. Olsen H, Hulthen UL, Lanne T. Reduced transcapillary fluid absorption from skeletal muscle and skin during hypovolaemia in insulin-dependent diabetes mellitus. J Intern Med (1999) 246(5):477-88. doi:10.1046/j.13652796.1999.00511.x

29. Ramasamy R, Yan SF, Schmidt AM. The diverse ligand repertoire of the receptor for advanced glycation endproducts and pathways to the complications of diabetes. Vascul Pharmacol (2012) 57(5-6):160-7. doi:10.1016/j. vph.2012.06.004

30. Hofmann B, Adam AC, Jacobs K, Riemer M, Erbs C, Bushnaq H, et al. Advanced glycation end product associated skin autofluorescence: a mirror of vascular function? Exp Gerontol (2013) 48(1):38-44. doi:10.1016/j.exger. 2012.04.011

31. Soldatos G, Cooper ME. Advanced glycation end products and vascular structure and function. Curr Hypertens Rep (2006) 8(6):472-8. doi:10.1007/ s11906-006-0025-8

32. Pop-Busui R, Low PA, Waberski BH, Martin CL, Albers JW, Feldman EL, et al. Effects of prior intensive insulin therapy on cardiac autonomic nervous system function in type 1 diabetes mellitus: the Diabetes Control and Complications Trial/Epidemiology of Diabetes Interventions and Complications study (DCCT/EDIC). Circulation (2009) 119(22):2886-93. doi:10.1161/ CIRCULATIONAHA.108.837369

Conflict of Interest Statement: The research was conducted in the absence of any commercial or financial relationships that could be construed as a potential conflicts of interest. No other conflict of interest exist.

Copyright $\odot 2016$ Lindenberger. This is an open-access article distributed under the terms of the Creative Commons Attribution License (CC BY). The use, distribution or reproduction in other forums is permitted, provided the original author(s) or licensor are credited and that the original publication in this journal is cited, in accordance with accepted academic practice. No use, distribution or reproduction is permitted which does not comply with these terms. 